\title{
“É TÃo DIFÍCIL ALGUÉM VESTIR NOSSOS CHINELINHOS": RELATOS DE MÃES DE CRIANÇAS COM TEA
}

\author{
Ana Caroline Bonato da Cruz \\ Psicóloga. Mestre em Educação pela Universidade Federal do Paraná \\ anacarolbcruz@gmail.com \\ Maria de Fátima Joaquim Minetto \\ Mestre em Educação pela UFPR. Doutora e Pós-Doutora em Psicologia pela UFSC Professora do \\ Departamento de Teoria e Fundamentos da Educação na Universidade Federal do Paraná. Curitiba \\ fa.minetto@gmail.com \\ Lidia Natalia Dobrianskyj Weber \\ Psicóloga. Mestre e Doutora em Psicologia Experimental pela USP. Pós-Doutora em Processos do \\ Desenvolvimento Humano e Saúde pela UNB. Professora sênior do Mestrado e Doutorado de Educação da \\ Universidade Federal do Paraná. \\ lidiaw@uol.com.br \\ Lurdes Fabricio de Oliveira \\ Psicóloga. Especialista em Psicopedagogia e em Educação Especial Inclusiva. Mestre em Educação pela \\ Universidade Federal do Paraná. \\ lurdesfabricio@gmail.com \\ Cassandra Fontoura Fiore Peron \\ Psicóloga. Especialista em Psicopedagogia, Educação Especial, Psicomotricidade e Neuropsicologia. Mestre \\ em Educação pela Universidade Federal do Paraná. \\ cassandraffperon@gmail.com
}

Recepción Artículo: 16 mayo 2021

Admisión Evaluación: 17 mayo 2021

Informe Evaluador 1: 26 mayo 2021

Informe Evaluador 2: 28 mayo 2021

Aprobación Publicación: 02 junio 2021

\section{RESUMO}

Envolver famílias de crianças com deficiência no tratamento é uma mudança iniciada na década de 60 que se consolida cada vez mais. Pais e mães de crianças com Transtorno do Espectro Autista (TEA) fazem parte deste grupo que pode se beneficiar de tais intervenções. 0 objetivo desta pesquisa é identificar potencialidades e fragilidades da função parental a partir do relato de mães. A coleta de dados foi realizada com a aplicação do Programa de Qualidade na Interação Familiar - Especial que contou com dez participantes, todas mães de crianças com diagnóstico de TEA. Os encontros foram gravados e os áudios analisados a partir de semelhanças semânticas das falas das mães. Foram elencados três eixos temáticos: ser mãe de uma criança com autismo, meu filho autista e redes de apoio. As características do TEA repercutem em sobrecarga na função materna e na opção por práticas educativas parentais inadequadas. Limitações e sugestões para estudos futuros são discutidas.

Palavras-chave: transtorno do espectro autista; práticas educativas parentais; intervenção para pais 


\title{
“É TÃo DIFÍCIL ALGUÉM VESTIR NOSSOS CHINELINHOS”: RELATOS DE MÃES DE CRIANÇAS COM TEA
}

\begin{abstract}
"It's so difficult for someone to put our slippers on": report of mothers of children with asd. Involving families of children with disabilities in treatment is a change that began in the 1960s, which has become more and more consolidated. Fathers and mothers of children with Autism Spectrum Disorder (ASD) are part of this group that may benefit from such measures. The objective of this research is to identify strengths and weaknesses of the parental role from the mothers' report. Data collection was carried out through the application of the Brazilian Family Interaction Quality Program - a special interaction program that included ten participants, all mothers of children with ASD. The meetings were recorded and the audios analyzed for semantic similarities of the mothers' speeches. Three central themes were identified: being the mother of a child with autism, my autistic child and support networks. The characteristics of ASD have an impact on the role of the mother and on the options of inadequate parental educational practices. Limitations and suggestions for future studies are discussed.
\end{abstract}

Keywords: autistic spectrum disorder; parental educational practices; intervention for parents

\section{INTRODUÇÃO}

A família possui um importante papel no desenvolvimento infantil, sendo o primeiro sistema responsável pela interação e socialização da criança (Correa, Minetto \& Crepaldi, 2018). Na década de 60, os profissionais que tratavam de crianças com doenças crônicas e/ou deficiências ocupavam-se apenas com o repasse de informações aos familiares. Hoje, a família no tratamento representa uma mudança na compreensão do processo de desenvolvimento. Relação que se desenvolveu para a preocupação com as formas de enfrentamento utilizadas pelos pais (Pardo \& Carvalho, 2012).

A elaboração de intervenções direcionadas a pais de crianças com deficiência/atraso no desenvolvimento tem como propósito contribuir com o máximo desenvolvimento da criança, auxiliar na adesão a tratamentos, melhorar a compreensão dos pais sobre a condição da criança (determinantes biológicos, potencialidades e limitações), potencializar os pais, colaborar com os ajustes necessários nos papéis parentais (Coutinho, 2004; Minetto \& Lohr, 2016; Franco, 2016). Pais de crianças com o diagnóstico de Transtorno do Espectro Autista (TEA) representam um dos grupos que pode se beneficiar com tais intervenções.

0 Transtorno do Espectro Autista é um transtorno do desenvolvimento caracterizado por déficits na comunicação social e comportamentos repetitivos/restritivos (APA, 2014). A incidência do diagnóstico tem aumentado, sendo estimado que em 1 a cada 59 crianças sejam identificadas dentro do espectro (CDC, 2019). Fato que indica maior número de famílias convivendo diariamente com os sintomas do TEA, os quais variam tanto em intensidade quanto em frequência (Schmidt, 2017).

0 diagnóstico de TEA exige uma reorganização familiar, com a quebra do filho ideal, a adaptação ao filho real e as novas demandas que se apresentam (Smeha \& Cezar, 2011; Franco, 2015). Além disso, diversos sentimentos podem ser vivenciados como desespero, tristeza, sofrimento e dúvidas quanto ao futuro da família e da criança (Machado, Londero \& Pereira, 2018).

A família tende a se organizar a partir das necessidades e da rotina da criança com TEA, com cuidado especial na evitação de crises (Minatel \& Matsukura, 2014; Machado, Londero \& Pereira, 2018). A mãe é geralmente 0 cuidador principal, responsável pelas atividades de vida diária, transporte e cuidado com a saúde, de forma que frequentemente precisa parar de trabalhar fora de casa para assumir todos os compromissos (Sifuentes \& Bosa, 2010). Sobrecarga emocional e de cuidado são observadas nessas famílias, podendo estar relacionadas a demora do diagnóstico (Gomes, Lima, Bueno, Araújo \& Souza, 2017), falta de rede de apoio (Machado, Londero \& Pereira, 2018), dificuldade em lidar com os sintomas do TEA, dificuldade de comunicação (Meimes, Saldanha \& Bosa, 2015) e estratégias utilizadas pelos pais para aceitar a condição da criança (Sifuentes \& Bosa, 2010).

Intervenções direcionadas a pais e mães de crianças com TEA passam a ser necessárias em diferentes contextos (família, terapias, escola), para atender as necessidades desse público. A nível internacional há relatos do estudo piloto com o programa Parents Taking Action (PTC) realizado em 2017 (Magaña, Lopez \& Machalicek), a 
elaboração de um guia de intervenção para famílias com filhos com TEA baseado na Terapia de Aceitação e Compromisso (Lozano-Segura, Manzano-Léon \& Aguilera-Ruiz, 2017) e o Primare Care Stepping Stones Positive Parenting Program (PC SS Triple P) que foi aplicado em famílias que haviam recebido o diagnóstico de TEA há menos de um ano (Zand, Bultas, McMilliam, White, McNamara \& Pierce, 2017).

Em âmbito nacional também são presentes descrições de um grupo com enfoque psicoeducacional para familiares de pessoas com TEA (Semensato, Schmidt \& Bosa, 2010), treino de controle de estresse para mães de crianças com TEA (Moxotó \& Malagris, 2015) e a adaptação do Programa de Qualidade na Interação Familiar para famílias com filhos com TEA (Cruz, Minetto \& Weber, 2019).

Neste contexto, esta pesquisa teve como objetivo identificar potencialidades e fragilidades da função parental a partir de relatos e descrição de rotinas de mães durante o Programa de Qualidade na Interação Familiar Especial (Cruz, Minetto \& Weber, 2019).

\section{MÉTODO}

0 presente estudo caracteriza-se por ser uma pesquisa qualitativa, com alcance descritivo e de corte transversal (Sampieri, Collado \& Lucio, 2013).

\section{Considerações Éticas}

Este estudo foi apresentado ao Comitê de Ética em Pesquisa em Seres Humanos da Universidade Federal do Paraná como parte da pesquisa "Adaptação do Programa de Qualidade na Interação Familiar para famílias com filhos com deficiência" em 17 de dezembro de 2017. A referida pesquisa compõe a última fase do projeto "Estratégias de prevenção e promoção ao desenvolvimento da criança na perspectiva bioecológica", aprovado pelo Comitê de Ética com no de parecer 1.573.473.

\section{Participantes}

Esta pesquisa contou com dez participantes, todas mães de crianças com TEA, sendo que duas delas têm dois filhos com diagnóstico de autismo. A idade média das participantes é de 36,1 anos (dp=2,6), a escolaridade predominante é ensino superior completo $(n=6)$ e a maioria $(n=7)$ exerce trabalho fora de casa. Em relação ao estado civil, oito delas são casadas/vivem junto com o pai da criança e duas são divorciadas do pai da criança, sendo uma delas recasada. Quanto à guarda das crianças com pais divorciados: em um caso a guarda é compartilhada e no outro é unilateral (sendo a mãe a responsável). Na apresentação dos resultados, as participantes serão referidas com nomes fictícios.

Em relação aos filhos das participantes com diagnóstico de TEA, a idade média é de 7,5 anos (dp=1,9 anos) com predominância de meninos ( $n=8$ ). Além do laudo referente ao TEA (CID F84), uma das crianças possui diagnóstico de altas habilidades e outra apresenta má formação cerebral (lisencefalia). Quando ao nível do autismo, há predomínio do nível leve $(n=7)$. A maioria das crianças $(n=10)$ frequenta escola regular e realiza acompanhamento em serviços especializados.

\section{Instrumentos}

a) Programa de Qualidade na Interação Familiar - Especial (PQIF-Especial)

Este programa é uma adaptação do Programa de Qualidade na Interação Familiar (Weber, Salvador e Brandenburg, 2018) que visa proporcionar informações e reflexões de acordo com as necessidades particulares de famílias com filhos com TEA para maior conscientização sobre a parentalidade. Para detalhes da adaptação consultar Cruz, Minetto e Weber (2019).

b) Questionário Sociodemográfico

Questionário desenvolvido pelas pesquisadoras para esta pesquisa a fim de obter informações sobre o participante.

c) Questionário sobre a criança 


\section{“É TÃo DIFÍCIL ALGUÉM VESTIR NOSSOS CHINELINHOS": RELATOS DE MÃES DE CRIANÇAS COM TEA}

Este questionário foi elaborado para a presente pesquisa tendo como base a Entrevista sobre Impacto dos Transtornos Globais do Desenvolvimento na Família (Schmidt, 2002). Seu propósito é obter informações sobre o processo diagnóstico pelo qual a família passou, como o participante define a criança com TEA, quais os impactos observados na família após o diagnóstico, e como é realizada a divisão de tarefas entre os membros da família.

\section{Procedimentos}

a) Coleta de Dados

Os dados foram coletados durante a aplicação do PQIF-Especial. As famílias que frequentavam um Programa de Extensão, realizado em uma Universidade no sul do Brasil, e destinado as crianças com deficiência e suas famílias, receberam o convite para participar do PQIF-Especial via telefone. Aqueles que consentiram em participar indicaram outras famílias que poderiam se beneficiar do programa.

Foi realizada entrevista inicial individual antes do início do PQIF-Especial com cada participante, na qual foi explicado o funcionamento dos encontros, além de esclarecimentos e assinatura do TCLE (Termo de Compromisso Livre e Esclarecido) e aplicados os questionários. Os encontros aconteceram entre os meses de setembro e outubro de 2018 com frequência semanal e duração de duas horas cada.

b) Análise de Dados

0 processo de análise de dados foi realiza pautado em Bardin (2011) a partir do modelo fechado de categorias (categorias determinadas pelo pesquisador). 0 registro dos encontros realizado em áudio foi transcritos e 0 material resultante foi discriminado de acordo com os seguintes eixos: ser mãe de uma criança com autismo, meu filho autista e redes de apoio. Na transcrição de fala é utilizada a letra E seguida de número para identificar em qual encontro do PQIF-Especial foi realizada a referida fala (por exemplo E1 refere-se ao Encontro 1).

\section{RESULTADOS E DISCUSSÃO}

Os resultados obtidos com a categorização dos temas estão apresentados na Tabela 1. Cada eixo temático predefinido foi analisado individualmente de forma que foi possível identificar duas subcategorias que compõem cada eixo, assim como os subtemas referentes. Ressalta-se que foi realizada análise de todos os encontros realizados no PQIF-Especial, portanto, serão apresentados trechos referentes a vários encontros. 
Tabela 1- Descrição dos temas e subtemas obtidos na análise das falas dos encontros realizados no PQIF-Especial

\begin{tabular}{|c|c|c|}
\hline Eixo Temático & Categorias & Subcategorias \\
\hline \multirow{2}{*}{$\begin{array}{l}\text { Ser mãe de uma criança } \\
\text { com autismo }\end{array}$} & Sobrecarga & $\begin{array}{l}\text { - } \text { Rotina de Crises } \\
\text { - Práticas Educativas } \\
\text { Positivas } \\
\text { - Mediação entre os } \\
\text { filhos } \\
\text { - Viver em função dos } \\
\text { filhos }\end{array}$ \\
\hline & Estratégias de Resistência & $\begin{array}{l}\text { - Práticas Educativas } \\
\text { Negativas } \\
\text { - Explosões } \\
\text { - Foco nas } \\
\text { possibilidades e nas } \\
\text { conquistas }\end{array}$ \\
\hline \multirow{2}{*}{ Meu filho autista } & Desafios & $\begin{array}{l}\text { - Validar a capacidade } \\
\text { da criança } \\
\text { - Atrasos no } \\
\text { desenvolvimento } \\
\text { - Características do } \\
\text { TEA (Perfil } \\
\text { sensorial, rigidez, } \\
\text { ecolalia, crises) } \\
\text { - Desenvolvimento de } \\
\text { autonomia } \\
\text { - Futuro }\end{array}$ \\
\hline & Ressignificação & $\begin{array}{ll}\text { - } & \text { Pequenas } \\
\text { conquistas, grandes } \\
\text { vitórias } \\
\text { - } \text { Bons momentos } \\
\text { - Passo-a-passo } \\
\text { - } \text { Previsibilidade } \\
\text { - Uso funcional das } \\
\text { características da } \\
\text { criança } \\
\text { - Compreensão das } \\
\text { crises }\end{array}$ \\
\hline \multirow{2}{*}{ Redes de Apoio } & Atitudes dos outros & $\begin{array}{ll}\text { - } & \text { Julgamento } \\
\text { - } & \text { Falta de apoio } \\
\text { - } & \text { Incompreensão } \\
\text { - } & \text { Compreensão } \\
\text { - } & \text { Acolhimento } \\
\end{array}$ \\
\hline & $\begin{array}{l}\text { Estratégias de } \\
\text { enfrentamento }\end{array}$ & $\begin{array}{ll}\text { - } & \text { Organização da } \\
& \text { dinâmica da casa } \\
\text { - } & \text { Armadura } \\
\text { - } & \text { Evitação de crises } \\
\text { - } & \text { Apoio entre as mães }\end{array}$ \\
\hline
\end{tabular}




\section{“É TÃo DIFÍCIL ALGUÉM VESTIR NOSSOS CHINELINHOS”: RELATOS DE MÃES DE CRIANÇAS COM TEA}

\section{Ser mãe de uma criança com autismo}

A compreensão sobre a dimensão do que é "ser mãe" esteve presente em várias falas ao longo dos encontros do PQIF-Especial, como as transcritas' na sequência:

Meu trabalho? Digo eu sou mãe em tempo integral, né? Se pudesse responder seria isso! (Violeta² - E1)

Você consegue fazer academia e ainda ser mãe? Fazer exercício? (Violeta - E1)

Ainda não, mas é o meu próximo objetivo: começar academia. Estou em busca de alguma que tenha espaço kids. (Lírio - E1)

Acho que traz uma reflexão as fotos. Eu no carro vindo tava pensando as fotos que eu peguei e como eu peguei assim muito rápido daí como eu não escolhi outras fotografias eu pensei: mas será que eu tô vivendo só em função dela? Em torno dela? Né? Digamos assim eu já fui pensando eu não tinha que ter pego outras fotografias? Só que agora eu já peguei essas e tem isso agora. Mas também fiquei com essa preocupação e essa reflexão. (Tulipa, E3)

0 primeiro relato de Violeta representa um fenômeno também descrito por Machado, Londero e Pereira (2018), no qual a mulher é principalmente quem passa a trabalhar exclusivamente dentro de casa a fim de suprimir as necessidades da criança. Quando esta não é a realidade da mãe, surgem outras demandas como a discutida por Violeta e Lírio, a respeito de "fazer academia e ainda ser mãe", sugerindo a dificuldade em conciliar atividades de saúde/lazer com o exercício da maternidade. No Questionário sobre a Criança, nove participantes relataram que são raros os momentos em que saem sem o filho com diagnóstico de TEA.

Em consonância, os relatos refletem a organização da vida das participantes a partir da função materna, conforme já foi observado em outros estudos (Smeha \& Cezar, 2011; Minatel \& Matskura, 2012; Constantinidis et al., 2018). Para mães que trabalham fora de casa esta percepção nem sempre é tão clara. 0 relato de Tulipa evidencia isto, quando ela passa a ter uma inquietação sobre a centralização da filha a partir de uma dinâmica com fotos realizada no terceiro encontro do PQIF-Especial.

0 estresse parental tem sido uma característica frequentemente associada a pais de crianças com TEA (Moxotó \& Malagris, 2015). No relato a seguir é exemplificada a carga de estresse cotidiana das mães.

Eu acho que a gente não busca perfeição, eu acho que a gente busca proximidade com uma rotina possível, sabe? De a gente não viver todos os dias assim tendo uma série de pequenos contratempos durante o dia. Que é isso que eu acho que desgasta a gente todo dia. Você pode ter tido um final de semana incrível. Mas daí começa de manhã tem um chilique no café, daí um chilique porque aconteceu alguma coisa antes do almoço, daí o meu para pegar o ônibus, eu não respiro até às 5. Aí ele vem e começa tudo de novo. Seis e meia, 7 horas, 8, 10, até. Então é isso que eu acho que deixa a gente assim. Eu acho que a gente não quer perfeição. A gente quer ter uma rotina um pouco menos assim. Podia só uma vez. Não assim o dia inteiro. (Orquídea - E5)

A convivência com os sintomas do TEA é apontada como uma das fontes de sobrecarga aos cuidadores (Meimes, Saldanha \& Bosa, 2015). Estes sintomas se manifestam em intensidade e frequência diferentes (Schmidt, 2017) e refletem diretamente na forma e tempo em que as atividades de vida diária são realizadas. Características como rigidez, necessidade de estruturação, alterações sensoriais, foram frequentemente relatadas pelas participantes. 0 que parece atuar como maior sobrecarga é a ocorrência de crises, conforme pode ser observado no relato de Orquídea. 0 que também se reflete nas práticas educativas parentais, como é possível observar nos relatos a seguir:

Eu acho que a gente acaba cedendo muito, assim por causo da situação deles a gente acaba cedendo muito, pra gente não se estressar, pra não ter aquele estresse cedo já. (Girassol - E5)

E não subestimar a capacidade dos nossos autistas em fazer, porque a gente subestima muito. Mas ai coitado não pode, ai coitado nem fala como que vai fazer isso? A gente fica muito com esse ai coitado às vezes eu sei que eu tô, mas eu não consigo botar em prática. (Azaléia - E2)

[. . . d dai eu fiquei pensando: pra minha mais velha as regras eu vou jogando, aí cada vez mais ela tá tomando conta. Que é a ideia, que um dia eu não precisa mais ficar cobrando, que ela saiba, né? Ela vai tocando a vida. 
Aí a outra eu comecei a ver gente eu não dou nada pra coitada administrar da vida dela.. (Margarida - E2)

Os relatos das participantes Girassol, Azaléia e Margarida indicam que os sintomas do TEA despertam sentimentos nas cuidadoras que influenciam a escolha por determinadas práticas educativas com o propósito de evitar crises. As práticas educativas parentais referem-se aos comportamentos que estão na relação parental que tem 0 propósito de educar, cuidar e promover o desenvolvimento (Macarini, Martins, Minetto \& Vieira; 2010).

De acordo com a perspectiva de MacCoby e Martin, as práticas educativas parentais são compreendidas a partir de duas dimensões: exigência (referente ao número e tipo de exigências que os pais fazem) e responsividade (referente ao nível de compreensão dos pais em relação aos filhos) (Darling \& Steinberg, 1993). 0 relato das participantes sugere menor exigência para as crianças com TEA, o que implica em pouco incentivo ao desenvolvimento de autonomia. Minetto e Cruz (2018), em uma pesquisa com crianças com atraso de desenvolvimento, observaram que os pais dessa população tendem a fazer menor uso de controle e exigência, com pouco incentivo ao desenvolvimento de autonomia. Fator que, segundo as autoras, influência no desenvolvimento da adultez da pessoa.

Apesar dos obstáculos do exercício da maternidade, estratégias tanto para manter-se ativa na função materna, como para contribuir com o desenvolvimento desta criança fazem parte das vivências destas mães, como exposto na fala a seguir:

Mas acho que talvez essa seja uma característica de nós mães autistas, né. Que a gente precisa, não é que a gente quer. Desculpa gente. A gente precisa ser otimista. É muita coisa. A gente começa a ver a vida de um jeito completamente diferente. Depois que a gente percebe [. . . ] Porque se eu disser pra mim que não vai dar, aí não vai dar. Aí eu não vou nem ter força pra ajudar o Alecrim. (Camélia - E2)

\section{Meu filho autista}

0 momento de compartilhar em grupo sobre os filhos é aguardado com especial apreço, como conta a participante Girassol:

Por isso que eu falei que quando chega a parte dos filhos é assim! Cada conquista a gente né tem um sabor maior das ditas normais que ela falou né. Porque é aquele negócio né a gente pensa que não vai conseguir, né? E eles conseguem fazer aquilo sair de uma fralda, foi difícil, mas saiu. São muitos momentos. E cada conquista é uma alegria imensa pra gente, nossa falou a primeira palavra, fez não sei o quê, nossa que festa! (Girassol E4)

Na entrevista inicial e no primeiro encontro o predomínio foi de relatos otimistas, definições como "alegre", "carinhosa" e "criativa". Com o passar dos encontros houve maior abertura para a partilha dos momentos de angústia e esgotamento, o que esteve relacionado ao compartilhamento de desafios vivenciados por elas, tanto no manejo com os filhos como na compreensão de comportamentos. Acredita-se que isso foi possível devido a empatia entre as participantes, dada a similaridade de vivências e emoções entre elas. De forma que os obstáculos passaram a ser apresentados, como está explicito nos seguintes trechos de falas:

Então, não deu certo naquele momento, porque ela precisava almoçar. Ela tem aquela rotina, então não dá pra sair daquilo. Então isso foi um complicador. (Tulipa - E4)

Faz dois anos que ele faz isso e eu não consigo fazer ele parar [de se coçar]. A minha frustração é quando vejo a mão dele cheia de sangue (. . .) parece que aquilo acalma ele, parece que ele precisa daquilo, é muito estranho. (Camélia - E5)

E até coloquei aqui cortar o cabelo. Parece que tão matando o guri, ele não gosta que penteie o cabelo dele. (Camélia - E5)

Esse é um capítulo à parte das nossas vidas (Orquídea - E5)

Em meio aos obstáculos relatados por elas, geralmente descrevendo características do TEA, houve o compartilhamento de ressignificações sobre 0 que uma vez havia sido desafiador, mas foi transformado em desenvolvimento e conquista. As falas das mães referem longos períodos de angústia e incompreensão até a mudança de um comportamento ou compreensão da função do comportamento. A mãe Orquídea, ao compartilhar sua tarefa 


\section{“É TÃo DIFÍCIL ALGUÉM VESTIR NOSSOS CHINELINHOS": RELATOS DE MÃES DE CRIANÇAS COM TEA}

de casa sobre as competências do filho no quarto encontro, relatou exatamente este fenômeno ao dizer "Eu pus competências e os milagres, porque acho que de tanto que eu pedi pra Deus ele fez um milagre".

Ressalta-se a importância de que pais e mães possam olhar para o filho tal como ele é, sem as expectativas da criança ideal e sem as lentes do diagnóstico (Franco, 2015; Cappellaro-Kobren, Correa \& Minetto, 2017). Kaufmann (2016) explica a importância das crenças dos pais em relação aos filhos, pois elas atuam como um quadro de referência para o que irá acontecer. 0 autor esclarece que cada pessoa pode decidir se quer ou não assumir uma determinada crença para si, mas que é comum que as pessoas não questionem as crenças e não consigam identificar possibilidades ao que aparece como única opção. Ainda segundo o autor, no caso da criança com autismo, a mudança de lentes (crenças) está frequentemente ligada as potencialidades da criança.

Meimes, Saldanha e Bosa (2015) afirmam que a identificação de habilidades na criança com TEA contribui para a adaptação familiar a deficiência e para a saúde mental dos cuidadores. Esta transformação pode estar relacionada ao processo de re-idealização das mães. 0 que não significa a inexistência de obstáculos, mas sim que eles não paralisem o desenvolvimento da família e da criança. A compreensão dos significados dos comportamentos proporciona um novo olhar para a criança, como contam as próprias participantes:

Ele morde qualquer coisa que ele tá, cordão, tecido e a gente: para de morder isso! Você quer pano? Vou cortar pano para você comer! E brigando e a gente chamava muita atenção disso. E agora a gente tem uma explicação, então a gente aceitou de uma forma assim. Não é que a gente não fica falando não faz assim, mas é que agora é diferente. Tem noção de que a culpa não é dele. Tem vez que ele fala: eu não consigo, não consigo parar! Fala assim, então eu fico com pena, porque daí eu sei que ele tá tentando ele fala: tô tentando, tô tentando. Aí eu fico mal por estar insistindo em uma coisa que não é culpa dele. (Rosa - E5)

Eu falei que ia no mercado. Mas na cabeça dela era o outro mercado. Daí eu tive que fotografar os mercados: tem o X e tem o Y. Ela não conseguia verbalizar o que estava pensando, e a gente também não expressou o que estava pensando ninguém falou nada e daí gera um estresse. (Margarida - E2)

Os relatos de Rosa e Margarida refletem a importância de compreender a função dos comportamentos das crianças. Visto que diante do convite de elencar comportamentos inadequados das crianças, foi evidente que as queixas das mães quanto aos comportamentos estavam diretamente relacionadas aos sintomas do TEA que, em alguns casos, não era compreendido como uma manifestação do transtorno.

\section{Redes de Apoio}

A importância de redes de apoio para famílias com filhos com TEA tem sido pontuada na literatura (Smeha \& Cezar, 2011; Minetto \& Lohr, 2016; Constantinidis et al., 2018; Machado, Londero \& Pereira, 2018). 0 apoio social atua como amortecedor do estresse vivenciado pelas famílias, proporciona suporte emocional aos familiares e sentido de pertencimento (Bosa, 2006). Esse tema foi explorado nos relatos das participantes a partir tanto do apoio efetivo como da falta de apoio, como no exemplo a seguir:

Às vezes a família não quer saber, só quando ele tá lá em cima, entendeu? Só a parte boa. Ou nossa sabe o que eu sempre escuto? Sabe como os autistas são inteligentes, porque eles fazem isso fazem aquilo. Não é assim, né? Então o que eles querem saber é aquela coisa boa, bem superficial, mas aquele pântano que todo mundo vive do autismo, esse ninguém quer ouvir. (Orquídea - E2)

Além do relacionamento com a família, o relacionamento a nível social, englobando outras pessoas e situações que fazem parte do cotidiano familiar, apresentam-se desafiadores para estas famílias, como descrito nos relatos das participantes a seguir:

Aí eu esperei a primeira vaga de fila e falei assim eu vim negociar uma dívida assim, assim, só que tô com filho e ele é autista, é especial, você pode me dar uma vaga especial? Ela olhou pra mim, ela olhou pra ele. Falei assim: algum problema? Foi lá e me deu a vaga especial da prioridade. Aí quando chegou o prioritário todo mundo ficou me olhando porque eu pedi, né. (Azaleia - E6)

Um dia eu levei ele nesses parques, não lembro o nome, daí pedi pra moça passar e ela: não. Aí eu expliquei a situação dele, e ela: todos aqui estão aqui na fila. Eu só conversei com a moça na outra fila que disse que podia 
passar. Mas me deu uma raiva ela falar todos eles são. Eu falei que meu filho era especial, e ela: todos eles são. (Girassol-E6)

Os relatos de Azaléia e Girassol exemplificam a dificuldade de serem efetivamente cumpridos os direitos da pessoa com TEA, o que pode ser reflexo tanto da falta de conhecimento quanto da ausência de um fenótipo que caracterize 0 transtorno. 0 que faz com essas pessoas sejam mais frequentemente reconhecidas por seus comportamentos considerados socialmente inadequados, conforme é relatado por Orquídea:

É que o mundo acha que eles são crianças que não se comportam. Aí você fala que ele tem autismo e falam ah pois é, conheço um que faz isso, isso. Então não dá pra misturar as coisas. Ninguém olham nossos filhos como se fosse uma criança com um transtorno. É uma criança muito mal educada. Porque se joga no chão, chora, isso e aquilo. (Orquídea - E6)

Pontua-se que 0 item mais indicado pelas participantes, nas respostas da Escala de Impacto Familiar, como impactante na família foi o referente a dificuldade em se encontrar uma pessoa de confiança para cuidar do filho. Apreensão que pode ser comum entre mães, mas é possível levantar a hipótese de que tal preocupação seja mais intensa nestas mães, dada a frequente convivência com falta de compreensão e empatia. Outra hipótese possível, levantada por Sifuentes e Bosa (2010), é a de que a mãe se julgue a única capaz de cuidar bem da criança, demonstrando insegurança e falta de confiança diante a ofertas de ajuda realizadas por familiares e até mesmo pelo cônjuge.

A incompreensão é um fenômeno que perpassa os diferentes sistemas que a criança faz parte, independentemente de quão próximo este sistema é do cotidiano da criança, podendo a não aceitação começar na própria família (Constantinidis et al., 2018). A dificuldade de compreensão e envolvimento dos avós para com a criança com TEA na família apareceu nos relatos das participantes: "Meu pai ele se envolve assim o mínimo. É como se o Coentro não existisse pra ele."

A coparentalidade diz respeito a relação entre a criança e, pelo menos, dois adultos cuidados, que engloba divisão do trabalho parental, suporte e/ou sabotagem da função coparental, acordo e/ou desacordo em práticas parentais, gestão conjunta das relações familiares; tendo grande importância para 0 desenvolvimento familiar (Feinberg, 2002). A existência ou não de parceira com o marido/pai da criança foi bastante discutida entre as mães. Os relatos heterogêneos possibilitaram o conhecimento de outras realidades e estratégias para conseguir a contribuiç̧ão do parceiro, distintas das já realizadas ou conhecidas. Como aconteceu com as seguintes exposições realizadas ao longo do PQIF-Especial:

Achei assim um ganho sabe muito grande assim então eu acho que a gente se perceber e perceber que você não precisa levar nada nas costas, que você não é a dona da verdade, eu achava que eu era a dona da verdade. Pra mim foi uma semana ótima! Porque até semana passada era eu que sentava pra fazer lição com as crianças. Agora não. Agora as lições são feitas às 19 horas e o pai participa. (Camélia - E2)

Porque eu falei assim [para o marido]: eu preciso de tempo pra mim. Eu preciso de tempo pra eu tomar banho. Eu não quero você me enchendo o saco se eu demoro meia hora pra tomar banho, eu quero esse tempo, eu preciso desse tempo. E ele me respeita [. . .] Pequenos acordos, pequenos ajustes que a gente fez em casa. (Lírio-E5)

Os relatos de Camélia e Lírio indicam a possibilidade de mudança de divisão de trabalhos, visto que nos dois casos a família passa por uma transição com o intuito de diminuir a sobrecarga da mulher. A desigual divisão de tarefas é um fenômeno observado em famílias com filhos com TEA (Sifuentes \& Bosa, 2010). No entanto, as participantes indicaram os principais responsáveis por uma série de itens relacionados a vida da criança (Questionário sobre a Criança). Dos 14 itens elencados, somente em três deles destacam-se as mães como responsáveis principais. Nos demais a tarefa é compartilhada com o pai, irmãos e outros. Os dados da pesquisa sugerem uma modificação na organização da dinâmica do lar.

Nas falas das mães ainda foi possível identificar a importância da relação com a escola. Na apresentação dos filhos, a maioria optou por ressaltar sua opinião sobre escola (mesmo que essa informação não tenha sido solicitada). Das dez mães, oito declararam contentamento com os profissionais da escola e a forma como 


\section{“É TÃo DIFÍCIL ALGUÉM VESTIR NOSSOS CHINELINHOS": RELATOS DE MÃES DE CRIANÇAS COM TEA}

tratam a criança e a família. As duas mães com filhos em escola especial relataram descontentamento com o apoio escolar recebido ao longo do ano letivo.

0 uso de determinadas estratégias pelas participantes foi identificado nas falas e a partir de uma dinâmica realizada. Além das já descritas referentes as mães Lírio e Camélia, referente a reorganização da dinâmica familiar a fim de atender todas as tarefas e minimizar sobrecarga, outras estratégias de sobrevivência também foram compartilhadas, como a escolha pelos locais e momentos em que sair com a criança e como enfrentar os momentos de crise fora de casa. Além disso, as mães compartilharam as formas como enfrentam as situações de olhares adversos:

Primeiro eu escolhi o óculos. Pensei assim, algumas situações eu tinha vontade de esconder. De me esconder. Do comportamento da criança. Eu me esconder. Mas depois eu parei pra pensar que também pode ser assim, como eu falei, tipo eu finjo que, não olho pro lado (Girassol - E6)

Eu peguei a base pra mostrar isso que a gente não demonstra pros outros essa nossa fragilidade, por isso que eu acho que a gente tem uma armadura. A gente tá sempre forte, sempre na defensiva, sempre achando que tá tudo bem, mas lá por baixo da base não está nada bem. Mas pros outros a gente tem que aparentar sanidade, digamos assim, clareza, compreensão, essas coisas assim. Mas quem olha de fora acha que a gente tá superbem. (Orquídea - E6)

0 apoio realizado entre as próprias mães que tem filhos com TEA foi bastante evidenciado, como explica Orquídea: "É tão difícil alguém vestir os nossos chinelinhos, né? E entender o que a gente passa, a não ser nós mães, né que compartilhamos os mesmos problemas." Os relatos englobaram associações de pais e grupos informais em rede social. As participantes também demonstraram criar laços entre si, ofertar escuta empática e espaço seguro para a exposição de cada uma, como ocorreu neste exemplo:

Mas aqui estamos todas para te acolher, te receber, pra dar apoio. Éó, a parte difícil é agora, é o diagnóstico. Depois sabe Deus da onde a gente tira força pra acontecer umas coisas assim e a gente superar. (Orquídea - E3)

Em seu estudo, Constantinidis et al. (2018) também observaram, a partir de entrevistas com mães de crianças autistas, que as mães acabam se unindo a partir do sofrimento comum e que esta união favorece a responsividade diante as situações desafiadoras.

\section{CONSIDERAÇÕES FINAIS}

Com a realização do Programa de Qualidade na Interação Familiar - Especial foi possível se aproximar das vivências de mães de crianças com o diagnóstico de TEA, o que favorece o refinamento de estratégias direcionadas a tais famílias nos mais diferentes contextos. Os relatos das participantes sobre experiências que, por mais singulares que sejam, são formadas por características similares, sensibilizam para o desenvolvimento de empatia entre elas. Além disso, a estrutura do Programa de Qualidade na Interação Familiar - Especial permitiu a aprendizagem e conscientização de práticas educativas parentais positivas e contribuiu com 0 desenvolvimento do papel de mãe atípica.

A sobrecarga do exercício da maternidade foi ressaltada nos discursos das participantes, relacionadas a diversos fatores, como a rotina de crises e vida organizada em função do filho com TEA. Os sentimentos que perpassam a parentalidade apresentaram-se fundamentais para a escolha por determinadas práticas educativas e para a possibilidade de desenvolvimento da criança e da família. Ressignificar as expectativas e as características da criança é uma estratégia utilizada pelas mães que as aproxima do filho real. 0 reconhecimento de redes de apoio demonstrou-se importante para as participantes, envolvendo diferentes sistemas dos quais a família faz parte, com especial apreço pela rede formada entre as mães de crianças com TEA.

É importante destacar que a realização de outros estudos poderá contribuir para o conhecimento de realidades as quais vivem tais famílias. Esta investigação apresentada contemplou o discurso somente de mães. Entretanto, 0 estudo sobre 0 discurso de outros familiares, poderá ampliar o conhecimento sobre as vivências das famílias. Grupos com outros participantes, como pais, irmãos e avós, podem contribuir tanto com a estruturação de redes de apoio mais eficazes, como com a compreensão das relações a partir de diferentes percepções. 


\section{REFERÊNCIAS BIBLIOGRÁFICAS}

Associação Americana de Psiquiatria. (2014). DSM-5.

Bosa, C. A. (2006). Autismo: intervenções psicoeducacionais. Revista Brasileira de Psiquiatria, 28(Supl I), S47S53. doi: http://dx.doi.org/10.1590/S1516-44462006000500007

Cappellaro-Kobren, R., Correa, W. \& Minetto, M. F. (2017). Um olhar para a criança com deficiência sob a perspectiva da complexidade. In: E. Guérios, F. H. R. Piske, A. M. Soek, \& E. J. Silva (Org.). Complexidade e educação: diálogos epistemológicos transformadores. (Cap. 10). Curitiba: CRV.

Center for Disease Control and Prevention - CDC. (2019). Recuperado em 09 de janeiro de 2019, de https://www.cdc.gov/ncbddd/autism/data.html.

Cruz, A. C. B., Minetto, M. F. \& Weber, L. N. D. (2019). Adaptação do Programa de Qualidade na Interação Familiar para famílias com filhos com Transtorno do Espectro Autista. International Journal of Developmental $\begin{array}{lll}\text { and Educational } & \text { Psychology, } & \text { 399-408. }\end{array}$ http://www.infad.eu/RevistaINFAD/OJS/index.php/IJODAEP/article/view/1473

Coutinho, M. T. B. (2004). Apoio à família e formação parental. Análise Psicológica, 1(22), 55-64. Disponível em: http://www.scielo.mec.pt/scielo.php?script=sci_arttext\&pid=S0870-82312004000100006

Correa, W., Minetto, F. \& Crepaldi, M. A. (2018). Família como promotora do desenvolvimento de crianças que apresentam atrasos. Pensando Famílias, 22(1), 44-58. Disponível em: http://pepsic.bvsalud.org/scielo.php?script=sci_arttext\&pid=S1679-494X2018000100005

Darling, N. \&Steinberg, L. (1993). Parenting Style as a context: an integrative model. Psychological Bulletin, 113(3), 487-496. doi: http://dx.doi.org/10.1037/0033-2909.113.3.487

Franco, V. (2015). Introdução a intervenção precoce no desenvolvimento da criança: com a família, na comunidade, em equipe. Évora: Edições Aloendro.

Franco, V. (2016). Tornar-se pai/mãe de uma criança com transtornos graves do desenvolvimento. Educar em Revista, 59, 35-48. doi: http://dx.doi.org/10.1590/0104-4060.44689

Gomes, P. T. M., Lima, L. H. L., Bueno, M. K. G., Araújo, L. A, \& Souza, N. M. (2017). Autism in Brazil: a systematic review of Family challenges e coping strategies. Jornal de Pediatra, 91(2), 111-121. doi: http://dx.doi.org/10.1016/j.jped.2014.08.009

Kaufman, R. K. (2016). Vencer o Autismo. Lisboa: Papa-Letras.

Lozano-Segura, M. C., Manzano-Léon, A., Yanicelli, C. C. \& Aguilera-Ruiz, C. (2017). Propuesta de intervención em familiares de niños com TEA desde ACT para mejorar la convivência familiar e escolar. International Journal of Developmental and Educational Psychology, 1(4), 455-464. Retirado de: http://www.infad.eu/RevistaINFAD/OJS/index.php/IJODAEP/article/view/897/778

Macarini, S. M., Martins, G. F., Minetto, M. F. J. \& Vieira, M. L. (2010). Práticas parentais: uma revisão de literatura. Arquivos brasileiros de psicologia, 62(1), 119-134. Retirado de:

Machado, M. S., Londero, A. D. \& Pereira, C. R. R. (2018). Tornar-se família de uma criança com Transtorno do Espectro Autista. Contextos Clínicos, 11(3), 335-350. doi: 10.4013/ctc.2018.113.05

Magaña, S., Lopez, K. \& Machalicek, W. (2017). Parents Taking Action: A Psycho-Educational Intervention for Latino Parents of Children with Autism Spectrum Disorder. Family Process, 56, 59-74. doi: 10.1111/famp.12169

Meimes, A. M., Saldanha, H. C. \& Bosa, C. A. (2015). Adaptação Materna ao Transtorno do Espectro Autismo: relações entre crenças, sentimentos e fatores psicossociais. Psico, 46(4), 412-422. doi: http://dx.doi.org/10.15448/1980-8623.2015.4.18480

Minatel, M. M. \& Matsukura, T. S. (2014). Famílias de crianças e adolescentes com autismo: cotidiano e realidade em diferentes etapas do desenvolvimento. Revista de Terapia Ocupacional da Universidade de São Paulo, 25(2), 126-134. doi: http://dx.doi.org/10.11606/issn.2238-6149.v25i2p126-34 


\section{“É TÃo DIFÍCIL ALGUÉM VESTIR NOSSOS CHINELINHOS": RELATOS DE MÃES DE CRIANÇAS COM TEA}

Minetto, M. F. \& Löhr, S. S. (2016). Crenças e práticas educativas de mães de crianças com desenvolvimento atípico. Educar em Revista, 59, 49-64. doi: http://dx.doi.org/10.1590/0104-4060.44791

Minetto, M. F. \& Cruz, A. C. B. (2018). Práticas Educativas Parentais: autonomia e expressão de afeto. International Journal of Developmental and Educational Psychology, 1(1), 155-164. http://dx.doi.org/10.17060/ijodaep.2018.n1.v1.1181

Moxotó, G. F. A. \& Malagris, L. E. N. (2015). Avaliação do treino de controle do stress para mãos de crianças com transtorno do espectro autista. Psicologia: Reflexão e Crítica, 28(4), 772-779. doi: 10.1590/16787153.201528415

Pardo, M. L. P. \& Carvalho, M. M. S. B. (2012). Grupos de orientação de pais: estratégias para intervenção. Contextos Clínicos, 5(2), 80-87. doi: https://dx.doi.org/10.4013/ctc.2012.52.02

Sampieri, H. E., Collado, F. C., \& Lucio. B. P. M. (2013). Metodologia de pesquisa. Porto Alegre: Penso.

Schmidt, C. (2002). Estresse, autoeficácia e o contexto de adaptação familiar de mães de portadores de Transtornos Globais do Desenvolvimento. Tese de Mestrado. Universidade Federal do Rio Grande do Sul.

Schmidt, C. (2017). Transtorno do Espectro Autista: onde estamos e para onde vamos. Psicologia em Estudo, 22 (2), 221-230. doi:10.4025/psicolestud.v22i2.34651

Semensato, M. R., Schmidt, C. \& Bosa, C. A. (2010). Grupo de familiares de pessoas com autismo: relatos de experiências parentais. Aletheia, 32, 183-194. Recuperado em: http://www.periodicos.ulbra.br/index.php/aletheia/article/view/3532/2624

Sifuentes, M. \& Bosa, C. A. (2010). Criando pré-escolares com autismo: características e desafios da coparentalidade. Psicologia em Estudo, 15(3), 477-485. Recuperado em: http://www.scielo.br/pdf/pe/v15n3/v15n3a05.pdf

Smeha,L. N. \& Cezar, P. K. (2011). A vivência da maternidade de mães de crianças com autismo. Psicologia em Estudo, 16(1), 43-50. Recuperado de https://www.redalyc.org/articulo.oa?id=287122137006

Weber, L. N. D., Salvador, A. P. V. \& Bradenburg, 0. J. (2018). Programa de Qualidade na Interação Familiar: Manual Para Facilitadores [3ㄹa ed.]. Curitiba: Juruá.

Zand, D. H., Bultas, M. W., McMilliam, S. E., White, T., McNamara, D. \& Pierce, K. J. (2017). A pilot of a brief positive parenting program on children newly diagnosed with autism spectrum disorder. Family Process, 57(4), 901-914. doi: 10.1111/famp.12334.

\section{NOTAS}

1 Todas as falas estão escritas conforme foram ditas nos encontros realizados.

2 os nomes utilizados são fictícios e se referem a plantas. 